\title{
DIAGNÓSTICOS EQUIVOCADOS Y SOLUCIONES DEMAGÓGICAS ESTÁN “PARALIZANDO” LAS INICIATIVAS DE LOS PRODUCTORES RURALES
}

\section{Polan Lacki}

Rua Bispo Dom José, 2051 apto 706. Telef: (55-41) 3243-2366 Celular: (55-41) 9602-1239

80440-080 Curitiba - Paraná - Brasil. E-mails: Polan.Lacki@uol.com.br y Polan.Lacki@onda.com.br

Websites: www.polanlacki.com.br y www.polanlacki.com.br/agroesp

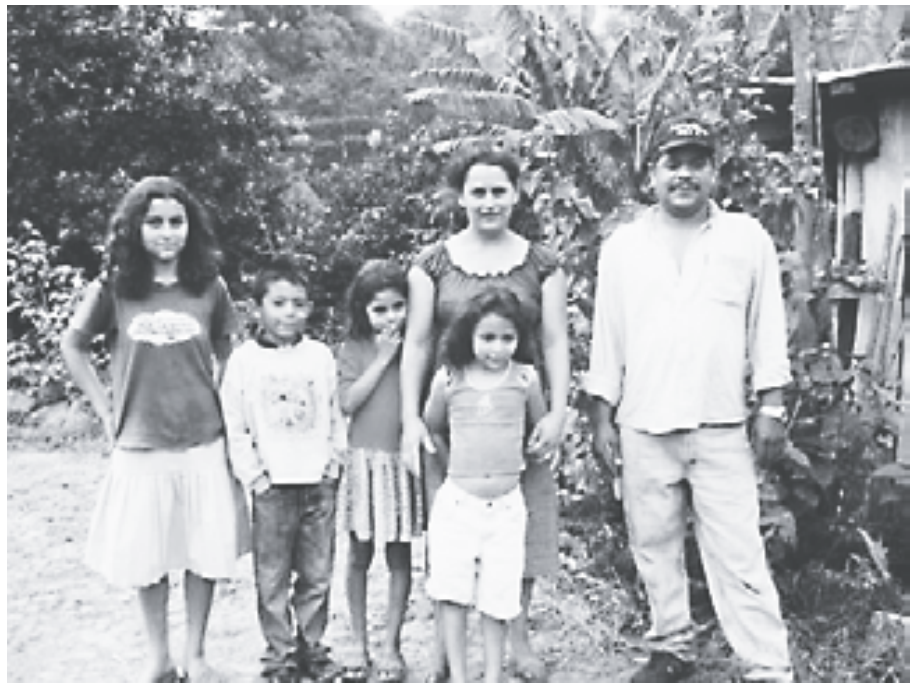

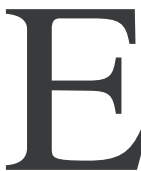

s profundamente lamentable que en América Latina hayamos perdido más de 50 años elaborando diagnósticos equivocados de la problemática rural y diciendo a los agricultores que los siguientes factores exógenos fueron o siguen siendo las principales causas de sus problemas:

- El colonialismo y el imperialismo.

- Las políticas de ajuste "impuestas" por el FMI y el Banco Mundial.

- El neoliberalismo, la globalización y la OMC.

- La falta de políticas, de garantías de comercialización, de créditos abundantes y baratos, de refinanciación y condonación de deudas.

- La falta de subsidios internos y medidas de protección contra la importación de productos agrícolas.

- El valor del dólar y el precio de los peajes.

- Los subsidios y protecciones que los países ricos ofrecen a sus agricultores.

Este planteamiento contiene algunas verdades y es muy redituable en términos electorales. Sin embargo: a. ¿Las causas eliminables de los problemas de los agricultores y las soluciones factibles de ser llevadas a la práctica son realmente las recién mencionadas? ¿O será que los "enemigos externos" son una excelente justificación y excusa para ocultar nuestra incapacidad de eliminar, nosotros mismos, nuestros "enemigos internos", utilizando las herramientas de la tecnología, de la administración y organización rural y del profesionalismo?

b. ¿Cuándo los agricultores eligen a sus líderes gremiales y a las autoridades del país será que lo hacen para que ellos sigan, ad infinitum, identificando supuestos culpables y proponiendo soluciones utópicas?; ¿ o lo hacen para que ellos adopten medidas realistas que puedan ser llevadas a la práctica, aún cuando no sea posible eliminar aquellos factores externos?

c. Cuando los agricultores, a través de sus impuestos, pagan los sueldos de los funcionarios de las instituciones de apoyo al agro, ¿lo hacen para que ellos sigan formulando diagnósticos de los motivos remotos, en el tiempo y en el espacio, del por qué somos subdesarrollados?; o lo hacen para que dichas instituciones se vuelvan muchísimo más eficaces en la corrección de las ineficiencias del negocio agrícola? 
d. ¿Antes de echar la culpa en terceros, no deberíamos "hacer las tareas domésticas", como por ejemplo, corregir las distorsiones descritas a continuación, máxime si tenemos en cuenta que éstas si, pueden ser evitadas o eliminadas, independiente de lo que ocurra o deje de ocurrir con aquellos "enemigos externos"?

1. En cada hectárea de tierra los agricultores latinoamericanos producen en promedio: $3189 \mathrm{~kg}$ de arroz; 712 kg de frijol; 3288 kg de maíz; 13.561 kg de papas; $2090 \mathrm{~kg}$ de trigo. No busquemos "chivos expiatorios", estos bajísimos rendimientos son consecuencia de errores primarios, fácilmente corregibles, como por ejemplo: utilizar semillas genéticamente erosionadas o contaminadas con patógenos, no hacer test de germinación, no inocular las semillas de leguminosas, no regular adecuadamente la sembradora, no hacer análisis de suelo, no adoptar la rotación y la diversificación de cultivos, no eliminar las malezas antes que ellas dañen el cultivo, no evitar pérdidas antes y durante la cosecha, etc.

En la ganadería los productores obtienen, en promedio, menos de 1200 litros de leche por vaca y por año; la primera preñez ocurre a los 33 meses de vida, pudiendo ocurrir antes de los 19 meses; el intervalo entre pariciones es de 22 meses, pudiendo ser de 13 meses; la extracción o saca es de 19\%, el rendimiento es de sólo 60 quilos de carne por hectárea y por año y los novillos llegan al peso de abate a los 50 meses de edad pudiendo hacerlo antes de los 25. Similar al caso de la agricultura, estos indicadores zootécnicos son el reflejo de la no adopción de prácticas también elementales, como por ejemplo: falta de cuidados en el parto incluso protección contra las intemperies, no desinfección del ombligo, no suministro del calostro en las primeras horas de vida, no adopción de medidas de prevención contra enfermedades y parásitos, falta de higiene en las instalaciones y en el ordeño, pérdidas de celos, falta de registros productivos y reproductivos, y, muy especialmente, porque los animales suelen estar sub o mal alimentados, durante largos períodos del año; la inadecuada o insuficiente alimentación, es, de lejos, la causa más importante del modesto desempeño de nuestra ganadería.

$\mathrm{Al}$ contrario de lo que suele afirmarse, estos errores no se deben a los supuestos factores exógenos mencionados en el primer párrafo de este artículo; ellos se deben al hecho concreto de que la mayoría de los productores-no por su culpa, evidentemente--no posee los conocimientos, elementales, que son necesarios para evitarlos o corregirlos.
2. Muchos agricultores aún practican el mono o bi cultivo y consecuentemente obtienen ingresos sólo una o dos veces al año. Es por esta razón, y no por falta de decisiones políticas, que se vuelven tan dependientes del crédito rural; si diversificasen la producción agrícola y la integrasen a la producción pecuaria también diversificada, podrían generar alimentos "balanceados" para la familia y para los animales, además de ingresos, durante los 365 días del año. Con esta medida, tan sencilla pero altamente eficaz, se volverían menos dependientes del crédito y menos vulnerables a otros factores externos adversos ( clima, mercado, plagas, etc ).

Soluciones pragmáticas, similares a la diversificación productiva, deberían ser enfatizadas en las escuelas agrotécnicas y facultades de ciencias agrarias; en vez de esperar que los economistas del Banco Central o los parlamentarios del Congreso Nacional resuelvan los problemas económicos de los agricultores. Es preferible eliminar ésta causa de la excesiva dependencia del crédito que contrarrestar sus síntomas o consecuencias, utilizando artificialismos crediticios compensatorios de ésta ineficiencia.

3. La mayoría de los productores rurales, mientras se quejan de la falta de recursos, sobredimensionan y mantienen en la ociosidad importantes inversiones en tierra, maquinaria e instalaciones que producen con bajos rendimientos y permanecen subutilizadas, durante gran parte del tiempo. Si los productores formasen grupos para ejecutar y utilizar en conjunto algunas inversiones (aquellas que son de alto costo y que son utilizadas con baja frecuencia) podrían reducir esta distorsión que incrementa, innecesariamente, sus costos fijos. Con los ahorros obtenidos podrían adquirir los insumos que necesitan (pero que dejan de comprar por no disponer de recursos) para aumentar los rendimientos y reducir los costos por kilo producido.

Idéntico problema ocurre con los animales; los ganaderos suelen poseer una excesiva cantidad de animales mal alimentados, en vez de tenerlos en menor cantidad, pero bien alimentados e consecuentemente más productivos. Estas sub utilizaciones y ociosidades no ocurren por falta de decisiones políticas o por culpa del colonialismo o del neoliberalismo, sino porque los agricultores no han sido formados ni capacitados para practicar el asociativismo, intensificar la producción y mejorar la administración predial; otra vez, la causa del problema y su solución no están en el Ministerio de Economía / Hacienda, sino que en el sistema educativo rural, formal y no formal. 
4. Los productores rurales más pobres suelen producir rubros de baja densidad económica que coincidentemente son consumidos por los habitantes urbanos de bajos ingresos, como por ejemplo: yuca, camote, papas, zapallo, maíz, arroz, frijol, etc. Produciendo estos "rubros consumidos por los pobres", aunque los productores fuesen eficientes y obtuviesen altos rendimientos por hectárea tendrían ingresos muy limitados pues estos cultivos, para proporcionar una mejor ganancia, necesitan de una gran escala de producción, ventaja que los pequeños no poseen. Consecuentemente es necesario capacitarlos para que produzcan rubros diferenciados, más sofisticados y de mayor densidad económica, como por ejemplo: cultivos orgánicos o hidropónicos, hortalizas bajo plástico para producirlas fuera de estación, frutas, flores y plantas ornamentales, champiñones, espárragos y otras hortalizas más sofisticadas, plantones, animales menores, miel, peces, gallinas y huevos criollos, condimentos, plantas aromáticas y medicinales, etc; y ojalá venderlos con algún valor agregado.

Con tal reconversión productiva dejarían de vender mucho ganando poco y pasarían a vender poco ganando mucho. La corrección de esta ineficiencia deberá ser enseñada por los agrónomos y zootecnistas directamente en la fincas, en vez de seguir pidiendo que los economistas del Banco Mundial o del FMI lo resuelvan allá en Washington.

5 y 6. Tanto en la adquisición de los insumos como en la venta de sus excedentes, los agricultores actúan en forma individual. Es debido a esta falta de espíritu y ejercicio asociativo, y no tanto por culpa de la globalización ni del FMI, que ellos adoptan procedimientos totalmente contrarios a sus propios intereses, como por ejemplo: en la compra de los insumos los adquieren al por menor, con alto valor agregado y del último eslabón de la cadena de intermediación; pero en la comercialización de sus excedentes, dan un giro de 180 grados y hacen exactamente lo contrario, pues los venden al por mayor, sin valor agregado, al primer eslabón de la cadena.

El espíritu cooperativo, la solidariedad y la práctica del asociativismo--necesarios para que los propios agricultores puedan revertir esta doble distorsión--hay que enseñárselos a los niños en las escuelas fundamentales rurales; en vez de seguir echándole la culpa a la OMC o a los países ricos que subsidian y protegen a sus agricultores. Seamos realistas y objetivos, los innecesariamente altos precios de los insumos y los innecesariamente bajos precios de las cosechas se deben, en gran parte, a la excesiva intermediación; y esta, a su vez, se debe al hecho de que los agricultores no han sido formados ni capacitados para organizarse con propósitos empresariales. En vez de mendigar que los supermercados, las agroindustrias o los intermediarios les paguen precios más justos por sus cosechas, los agricultores deberían exigir que el sistema educativo rural les enseñe cómo organizarse para disminuir los excesivos eslabones en la venta de sus cosechas.

Estos seis son los principales problemas solucionables, por los propios agricultores, que con mayor frecuencia afectan a la gran mayoría de ellos; estas son las principales causas eliminables que los provocan y estas son las soluciones posibles. Los problemas, las causas y las soluciones están, principalmente, en las propias fincas, en las comunidades rurales, en los tres niveles de la educación agrícola formal y en los servicios de extensión rural; no vale la pena perder demasiado tiempo buscándolas en Bruselas, en Ginebra, en Washington o en Tokio.

Si el sistema educativo rural proporcionase a las familias rurales, tan solamente, las competencias ( conocimientos, habilidades y actitudes ) que necesitan para corregir apenas estas seis ineficiencias, ellas mismas lo harían, reducirían los costos por kilo producido, mejorarían la calidad y agregarían valor a sus cosechas, incrementarían los precios de venta de sus excedentes, se autoabastecerían de alimentos, para la familia y para los animales, y asegurarían ingresos durante los 365 días del año. Si hiciesen tan solamente esto, tendrían mayor rentabilidad, serian más competitivos y además se volverían mucho menos dependientes de las ayudas de sus gobiernos y mucho menos vulnerables a los factores que ellos no pueden controlar (clima, mercado, falta de crédito, subsidios y protecciones de los países ricos, etc .).En fin, sus principales problemas estarían resueltos, por ellos mismos, independiente de lo que decidan o dejen de decidir sus propios gobiernos, los gobiernos de los países ricos, los organismos internacionales, etc. Si es así, por que no hacerlo? Todo lo anterior significa que estamos conduciendo a los productores rurales a una suerte de "parálisis" al magnificar la importancia de supuestos factores exógenos de desarrollo agrícola que están fuera del alcance de los agricultores $\mathrm{y}$ hasta de sus respectivos gobiernos; $\mathrm{y}$, mientras tanto, estamos subestimando la urgente necesidad de efectuar una profunda reforma en el sistema de educación rural, la cual dicho sea de paso, está al inmediato alcance de los más empobrecidos y desfinanciados gobiernos. 